
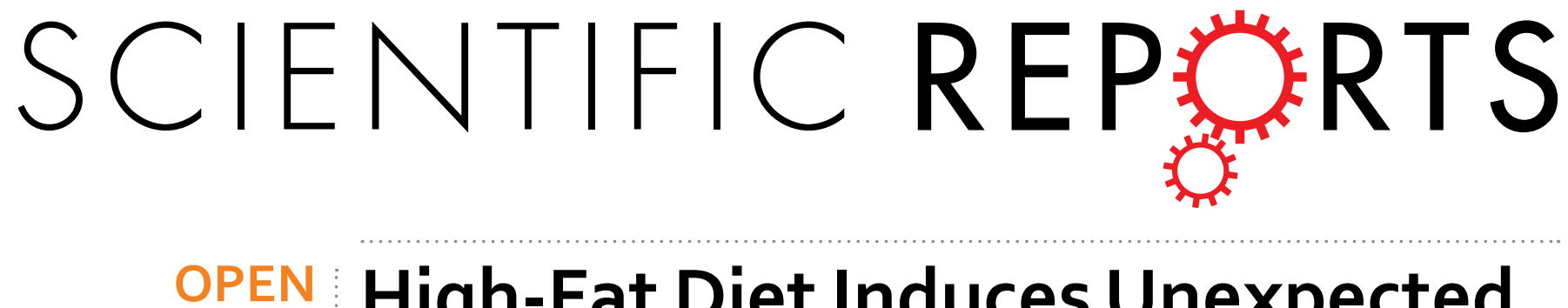

\title{
High-Fat Diet Induces Unexpected Fatal Uterine Infections in Mice with aP2-Cre-mediated Deletion of Estrogen Receptor Alpha
}

Zsofia Ban ${ }^{1}$, Paul Maurischat ${ }^{1}$, Verena Benz ${ }^{1}$, Sarah Brix ${ }^{1}$, Anna Sonnenburg ${ }^{2}$, Gerhard Schuler ${ }^{3}$, Robert Klopfleisch ${ }^{4}$, Michael Rothe ${ }^{5}$, Jan-Åke Gustafsson ${ }^{6}$, Anna Foryst-Ludwig ${ }^{1,7, *}$ \& Ulrich Kintscher ${ }^{1,7, *}$

Estrogen receptor alpha (ER $\alpha$ ) is a major regulator of metabolic processes in obesity. In this study we aimed to define the relevance of adipose tissue ER $\alpha$ during high-fat diet (HFD)-induced obesity using female aP2-Cre ${ }^{-l+} / \mathrm{ERO}^{\mathrm{fl} / \mathrm{f}}$ mice (atERoKO). HFD did not affect body weight or glucose metabolism in atER $\alpha$ KO- compared to control mice. Surprisingly, HFD feeding markedly increased mortality in atER $\alpha K O$ mice associated with a destructive bacterial infection of the uterus driven by commensal microbes, an alteration likely explaining the absence of a metabolic phenotype in HFD-fed atER $\alpha$ KO mice. In order to identify a mechanism of the exaggerated uterine infection in HFD-fed atER $\alpha$ KO mice, a marked reduction of uterine $\mathrm{M} 2$-macrophages was detected, a cell type relevant for anti-microbial defence. In parallel, atER $\alpha$ KO mice exhibited elevated circulating estradiol (E2) acting on E2-responsive tissue/cells such as macrophages. Accompanying cell culture experiments showed that despite E2 coadministration stearic acid (C18:0), a fatty acid elevated in plasma from HFD-fed atER $\alpha$ KO mice, blocks M2-polarization, a process known to be enhanced by E2. In this study we demonstrate an unexpected phenotype in HFD-fed atER $\alpha$ KO involving severe uterine bacterial infections likely resulting from a previously unknown negative interference between dietary FAs and ER $\alpha$-signaling during antimicrobial defence.

There is a growing body of evidence from human and rodent studies for a crucial role of estrogen and estrogen receptors (ERs), in particular ER $\alpha$, in the regulation of body weight ${ }^{1}$. Menopause is associated with loss of ligand-mediated ER-signaling causing increased adiposity and body fat redistribution ${ }^{2}$. The reconstitution of regular ER-signaling by hormone replacement can prevent menopause-mediated weight gain, and results in fat redistribution to subcutaneous fat depots, and improvement of insulin sensitivity ${ }^{3}$. According to these studies, female rodents become obese after undergoing ovariectomy, and replacement of estrogens abrogates BW-gain ${ }^{4}$. Similar to the ligand-deficient models, the ER $\alpha$-knock out mice exhibit increased BW and fat mass without a concomitant change in food consumption but a significantly reduction of energy expenditure compared to wild-type animals ${ }^{5}$. Deficiency of ER $\beta$ also results in increased body weight ${ }^{6}$. In contrast to ER $\alpha$-knock out mice, loss of $\mathrm{ER} \beta$ leads to an improvement of insulin and glucose metabolism ${ }^{6}$. Despite the metabolic characterization of both isoforms, it has become increasingly clear that ER $\alpha$ is the predominant regulator of body weight and glucose/ lipid metabolism ${ }^{7}$.

$\mathrm{ER} \alpha$ mediates its metabolic actions via the central nervous system (CNS) and via peripheral organs/cells such as adipose tissue and macrophages ${ }^{7-9}$. Regarding ER $\alpha$ 's CNS actions, Xu and colleagues previously phenotyped

${ }^{1}$ Charité-Universitaetsmedizin Berlin, Institute of Pharmacology, Center for Cardiovascular Research, Berlin, Germany. ${ }^{2}$ Charité-Universitaetsmedizin Berlin, Institute of Clinical Pharmacology and Toxicology, Berlin, Germany. ${ }^{3}$ Clinic for Obstetrics, Gynaecology and Andrology of Large and Small Animals, Faculty of Veterinary Medicine, Justus-Liebig-Universität Gießen, Germany. ${ }^{4}$ Department of Veterinary Pathology, College of Veterinary Medicine, Freie Universität Berlin, Berlin, Germany. ${ }^{5}$ Lipidomix GmbH, Berlin, Germany. 6 University of Houston, Center for Nuclear Receptors and Cell Signaling, Houston, TX, USA. ' DZHK (German Centre for Cardiovascular Research), partner site Berlin, Germany. ${ }^{*}$ These authors contributed equally to this work. Correspondence and requests for materials should be addressed to U.K. (email: ulrich.kintscher@charite.de) 


\begin{tabular}{|l|c|c|}
\hline & wt & atER $\alpha$ KO \\
\hline Body weight $[\mathrm{g}]$ & $19.28 \pm 0.55$ & $22.80 \pm 0.41^{* * *}$ \\
\hline Locomotor acitivty $[\mathrm{cnts} / \mathrm{d}]$ & $91477 \pm 10009$ & $81981 \pm 7452$ \\
\hline Food intake $[\mathrm{kcal} / \mathrm{d}]$ & $12.50 \pm 1.38$ & $12.11 \pm 0.85$ \\
\hline Body temperature $\left[{ }^{\circ} \mathrm{C}\right]$ & $37.36 \pm 0.10$ & $37.26 \pm 0.11$ \\
\hline Energy expenditure $[\mathrm{kcal} / \mathrm{h} / \mathrm{kg}$ lean mass] & $27.93 \pm 0.81$ & $23.79 \pm 0.69^{* *}$ \\
\hline Lean mass $[\mathrm{g}]$ & $15.30 \pm 0.47$ & $17.94 \pm 0.64^{*}$ \\
\hline Fat mass[g] & $1.96 \pm 0.11$ & $2.03 \pm 0.06$ \\
\hline
\end{tabular}

Table 1. Metabolic phenotyping of 6 weeks old female mice on $\mathrm{CD} . \mathrm{N}=5$. Two-tailed t-test. ${ }^{\star} \mathrm{P}<0.05$; ${ }^{* *} \mathrm{P}<0.01 ;{ }^{* * *} \mathrm{P}<0.001$.

CNS-specific ER $\alpha$ knock-out mice ${ }^{10}$. The authors demonstrated that floxed-ER $\alpha$ mice crossed with Nestin-Cre transgenic mice, show ER $\alpha$ loss in most brain regions, exhibit decreased locomotor activity, abdominal obesity and reduced energy expenditure, a phenotype similar to complete ER $\alpha$-deficient animals ${ }^{10}$. ER $\alpha$-deletion in neurons of the ventromedial hypothalamic nucleus $(\mathrm{VMH})$ resulted in reduced energy expenditure, and deletion in pro-opiomelanocortin (POMC) neurons led to hyperphagia ${ }^{10}$. These data delineate the metabolic CNS-effects of ER $\alpha$ involving an increase of energy expenditure and a suppression of food intake. The peripheral metabolic actions of ER $\alpha$ are less well understood. Ribas and colleagues demonstrated that a loss of ER $\alpha$ in myleoid cells results in increased adipose tissue mass, insulin resistance and glucose intolerance ${ }^{9}$. In addition, ER $\alpha$ acts in white adipose tissue, and enhances subcutaneous white adipose tissue distribution while decreasing overall adipose mass involving a reduced FFA-uptake, lipid synthesis and increasing lipolysis ${ }^{7,8,11}$. In addition, ER $\alpha$ protects against adipose tissue inflammation and fibrosis ${ }^{8}$.

To determine the role of adipose tissue $\mathrm{ER} \alpha$ for body weight regulation and whole body insulin and glucose metabolism, mice were generated lacking ER $\alpha$ in adipose tissue (aP2- $\mathrm{Cre}^{-/+} / \mathrm{ER}^{\mathrm{fl} / \mathrm{fl}}$ mice) and control littermates (aP2-Cre ${ }^{-1-} / \mathrm{ER}^{\mathrm{fl} / \mathrm{fl}}$ mice) (wt). These mice were kept on a high fat diet (HFD). Surprisingly, atER $\alpha$ KO mice on HFD did not differ in body weight, insulin sensitivity or glucose tolerance compared to wt-mice. More importantly, HFD feeding markedly increased mortality in atER $\alpha \mathrm{KO}$ compared to wt controls and atER $\alpha \mathrm{KO}$ mice fed control diet (CD). HFD-induced mortality resulted from massive and fatal bacterial uterine infections in atER $\alpha \mathrm{KO}$ mice. We identified that dietary fatty acids markedly attenuate ER $\alpha$-signaling in macrophages accompanied with impaired neutrophil clearance during bacterial infection subsequently leading in a multifactorial context to aggravated infections.

In summary, this study identifies an unexpected phenotype in HFD-fed atER $\alpha$ KO mice pointing towards a crucial interaction between dietary fatty acids and ER $\alpha$-signaling during bacterial infections.

\section{Results}

No metabolic phenotype but increased mortality in HFD-fed atER $\alpha$ KO mice. Metabolic baseline characterization of 6 weeks old female atER $\alpha \mathrm{KO}$ mice resulted in the expected metabolic phenotype with increased body weight (BW) and decreased energy expenditure (Table 1). However, in 15 weeks old wt- and atER $\alpha \mathrm{KO}$ mice on control diet (CD) BW-differences disappeared (Fig. 1A). More importantly, HFD-induced increase of BW after 14 weeks feeding did not differ between wt- and atER $\alpha$ KO mice (Fig. 1A,B). Along this line, no differences could be detected for glucose tolerance and insulin sensitivity between wt- and atER $\alpha$ KO mice after HFD-feeding (Fig. 1C,D). Neither energy expenditure nor locomotor activity, assessed by metabolic cage experiments, showed any alteration in the HFD-fed atER $\alpha$ KO group when compared to control (Fig. 1E,F). However, mutant mice displayed an increase in food intake (Fig. 1G). These data appeared highly controversial to recently published results about the role of ER $\alpha$ in adipose tissue pointing towards a protective action of ER $\alpha$ against BW gain and HFD-mediated glucose intolerance ${ }^{7}$. Expression analysis of metabolically relevant genes in white adipose tissue showed only modest effects of $E R \alpha$, reaching statistical significance only for the reduction of ATGL expression in the absence of $\mathrm{ER} \alpha($ Fig. $1 \mathrm{H})$. These data corroborate our previous findings pointing to a pivotal role of ER $\alpha$ in lipolysis ${ }^{12}$. Surprisingly, after the onset of HFD-feeding we observed a markedly increased mortality in HFD-fed atER $\alpha$ KO mice compared to atER $\alpha$ KO mice on CD and to wt-mice (Fig. 1I). Together these data suggest that HFD-feeding induces a fatal pathology in atER $\alpha \mathrm{KO}$ which likely impacts on physiological metabolic processes.

HFD mediates fatal uterine infections in atER $\alpha \mathrm{KO}$ mice. Autopsies of wt- and atER $\alpha \mathrm{KO}$ mice revealed massive uterine fluid accumulation in $\mathrm{CD}$-fed atER $\alpha \mathrm{KO}$ mice compared to wt-mice as previously described (Fig. 2A) ${ }^{13}$. More importantly, HFD-feeding aggravated these uterine processes in atER $\alpha$ KO mice leading to a destructive, pus-filled swelling of the uterus and uterine appendages in line with a severe bacterial infection in all HFD-fed atER $\alpha \mathrm{KO}$ mice (Fig. 2A, right panels). In consonance, microbiological analysis of the uterine fluid of HFD-fed atER $\alpha$ KO mice showed the presence of commensal microbes including Enterococcus sp. and bacterial DNA for E.coli (data not shown). These results were confirmed by histological analysis (Fig. 2B) demonstrating massive cellular infiltration of the uterine wall in HFD-fed atER $\alpha$ KO accompanied by destruction of the intramural glandular and epithelial structure (Fig. 2B, right panels). The grade of uterine inflammation as determined by microscopic analysis (for detailed protocol see methods) was significantly higher in atER $\alpha$ KO mice fed HFD vs. CD (Fig. 2C). CD- or HFD-fed wt-mice showed no evidence for uterine inflammation (data not shown). Bacterial uterine infections in HFD-fed atER $\alpha$ KO mice were characterized by pronounced neutrophil 
A

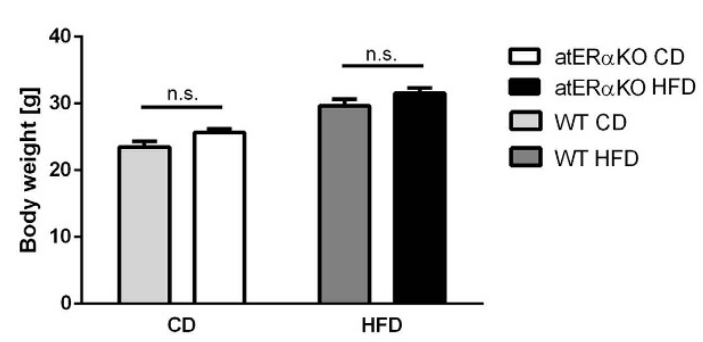

C

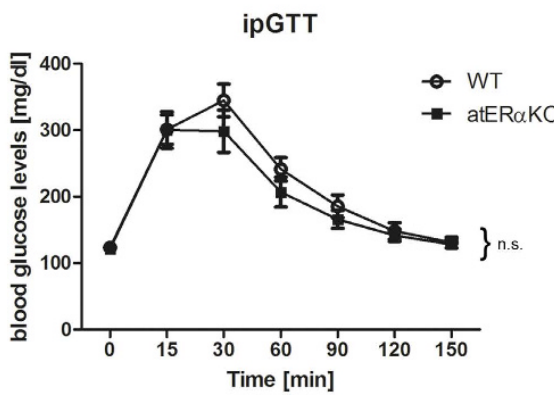

B

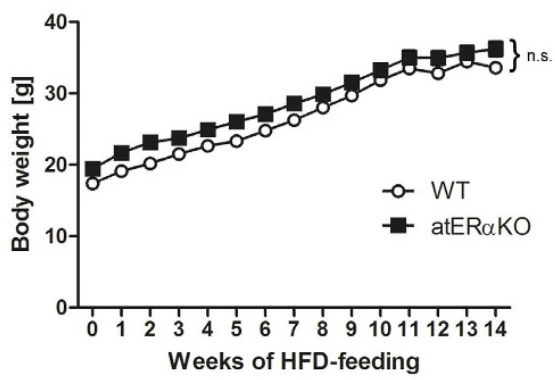

D

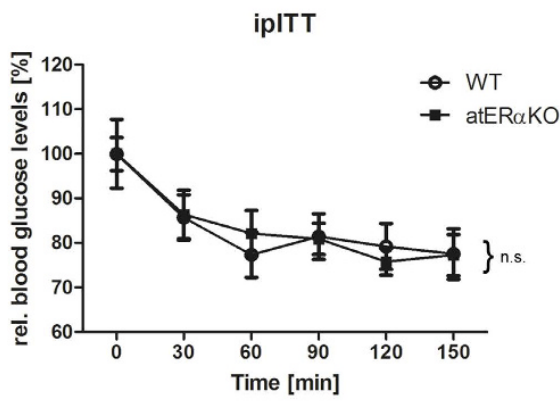

E

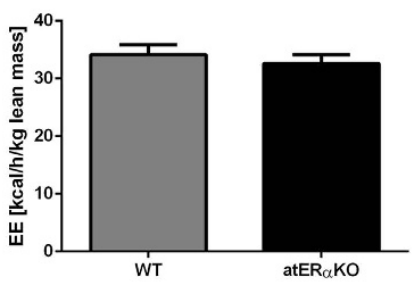

$\mathrm{H}$

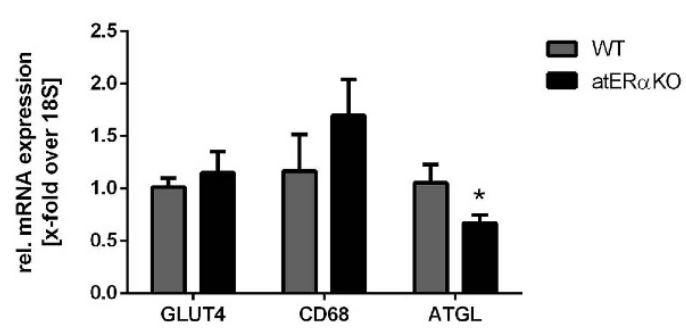

।

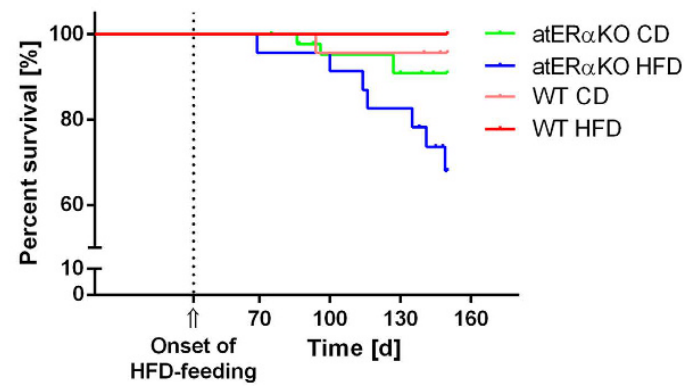

Figure 1. Metabolic phenotyping of female atER $\alpha$ KO mice. (A) Body-weight of atER $\alpha$ KO- compared to wt-mice fed a control (CD) or a high-fat diet (HFD) at the age of 15 weeks. ( $=5$ (CD) and 17-19 (HFD)). (B) Body weight development during HFD-feeding, showing no differences between genotypes. (C,D) Intraperitoneal glucose- $(C)$ and insulin- $(D)$ tolerance test $(n=9-10)$. No differences occurred in energy expenditure $(\mathrm{E})$ and in locomotor activity $(\mathrm{F})$ between the genotypes, while atER $\alpha$ KO mice showed an increase in food intake $(\mathbf{G})(\mathrm{n}=10)$. $(\mathbf{H})$ Gene expression analyses in white adipose tissue of wt and atER $\alpha \mathrm{KO}$ mice $(n=5-8)$. (I) Survival curves of atER $\alpha K O$ - and wt-mice on CD and HFD. Onset of HFD-feeding at 42 days of age is indicated in the graph. n.s. = non-significant $(\mathrm{P}>0.05,2$-way-ANOVA (Bonferroni-posttest) and 2-wayANOVA with repeated measures (Bonferroni-posttest)). ${ }^{\star} \mathrm{P}<0.05$ vs. wt (two-tailed t-test).

accumulation associated with a low number of macrophages in the uterine wall (Fig. 2D,E). Neutrophils initially recruited to the site of bacterial infection are usually cleared by macrophages to initiate physiological resolution and to prevent exaggeration of inflammation, a process called efferocytosis ${ }^{14}$. Regular macrophage-mediated 
A
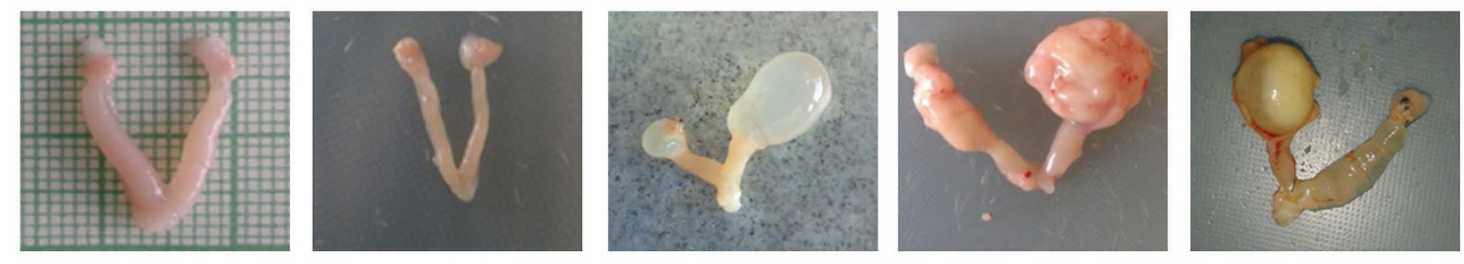

WT

HFD

HFD -

$+$

HFD

atERaKO

B
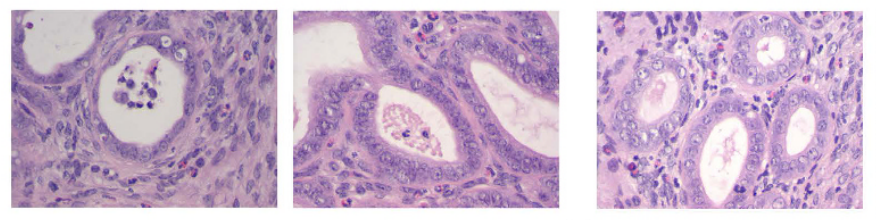

WT

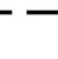

HFD -

HFD

C

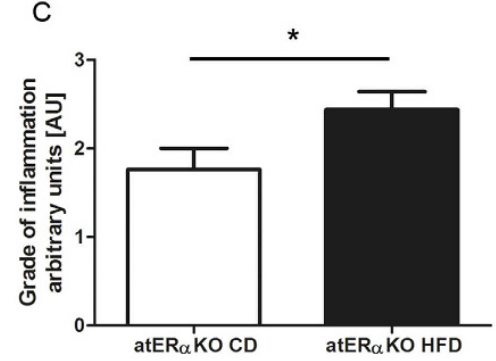

E

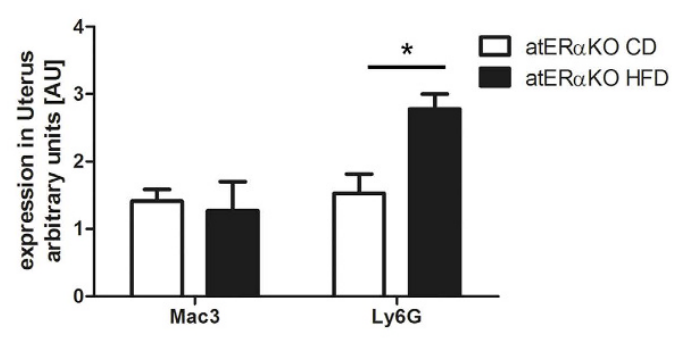

F

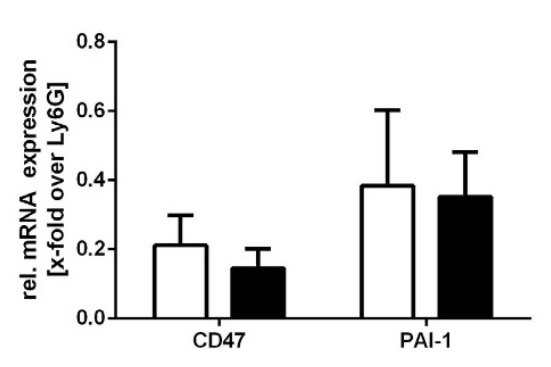

G

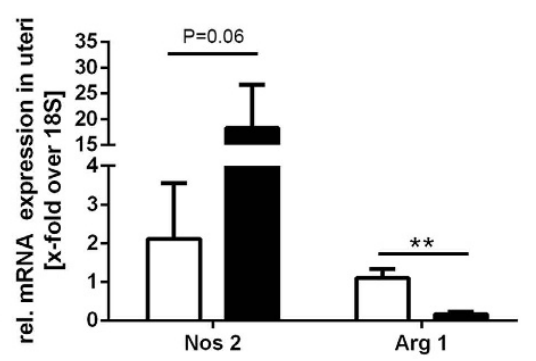

D
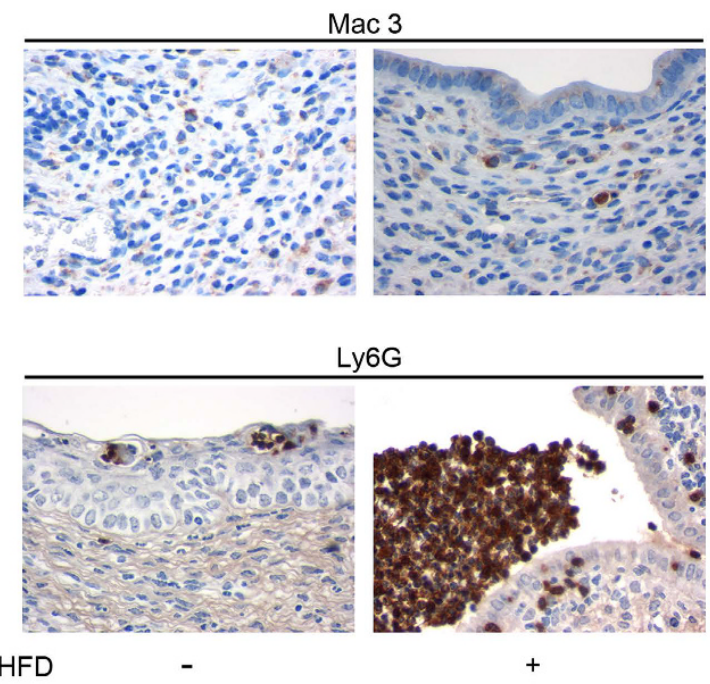

$\mathrm{H} \square$ atER $\alpha$ KO CD

Figure 2. Characterization of uterine phenotype. $(A, B)$ Representative macro- and microscopic images of uteri of atER $\alpha$ KO vs. wt-mice fed a CD or HFD. (C) Quantification of the grade of inflammation $(n=9-17)$. Legend: $0=$ no inflammation; $1=$ beginning inflammation; $2=$ visible inflammation; $3=$ severe inflammation (D) Representative Mac3- and Ly6G-stainings. (E) Quantification of macrophages (Mac3) and neutrophils (Ly6G) in uteri of atER $\alpha$ KO mice $(n=9-17)$. Legend: $0=$ no immune cells; $1=$ few immune cells; $2=$ high quantity of immune cells; $3=$ very high quantity of immune cells (F) Relative mRNA-expression of CD47 and PAI-1 normalized to Ly6G mRNA-expression in uteri, comparing atER $\alpha$ KO mice on CD or HFD $(n=4-7)$. Relative Nos2 and Arg1 mRNA expression in uteri (G) and white adipose tissue (H) of atER $\alpha$ KO mice $(\mathrm{n}=7-8) .{ }^{*} \mathrm{P}<0.05,{ }^{* *} \mathrm{P}<0.01$ two-tailed t-test or 2 -way-ANOVA (Bonferroni-posttest). 
A

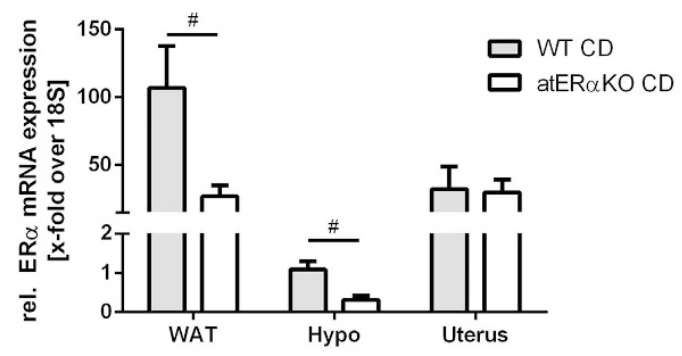

C

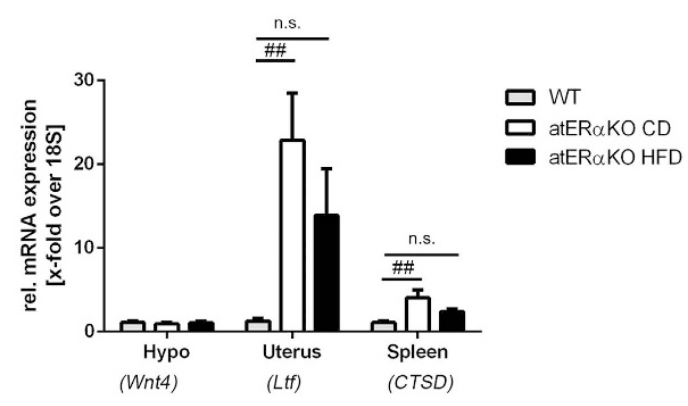

B

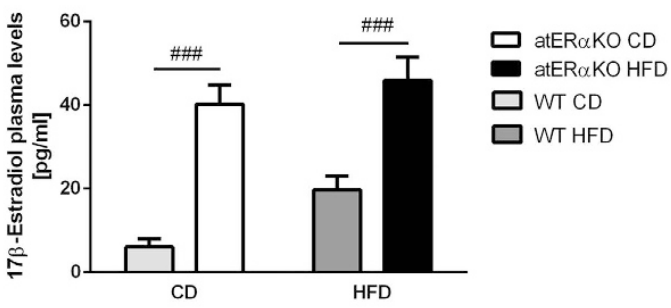

$\mathrm{D}$

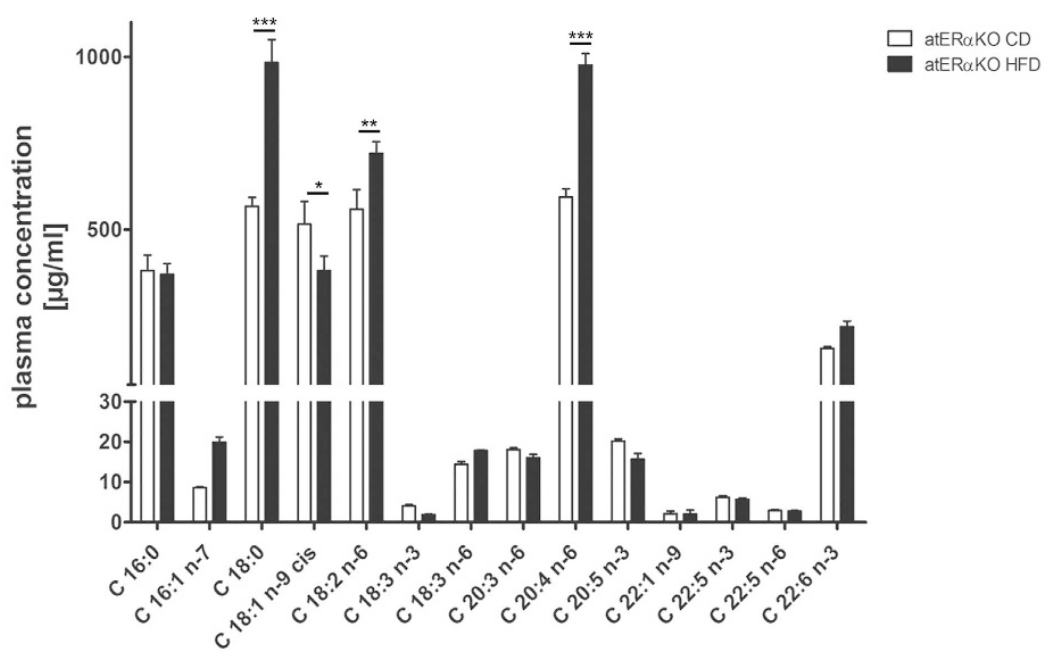

Figure 3. ER $\alpha$-signaling and lipid profile of atER $\alpha$ KO mice. (A) Relative ER $\alpha$ mRNA-expression in indicated tissues $(n=5)$. (B) $17 \beta$-estradiol levels in plasma of female atER $\alpha$ KO- and wt-mice $(n=5-10)$. (C) Relative mRNA expression of ER $\alpha$-target genes in hypothalamus (Wnt4), uterus (Ltf) and spleen (CTSD) in CD or HFD-fed atER $\alpha$ KO- and wt-mice (WT) $(n=4-8)$. (D) Measurement of plasma concentration of fatty acids in HFD-fed atER $\alpha$ KO mice vs. CD-fed $(\mathrm{n}=3)$. ${ }^{*} \mathrm{P}<0.05,{ }^{* *} \mathrm{P}<0.01,{ }^{* * *} \mathrm{P}<0.001$ vs. atER $\alpha \mathrm{KO} \mathrm{CD}$; ${ }^{\#} \mathrm{P}<0.05,{ }^{\# \#} \mathrm{P}<0.001$ vs. WT; one-way ANOVA, 2 -way-ANOVA or unpaired t-test.

neutrophil clearance depends on specific neutrophil marks to engage particularly M2-macrophages ${ }^{14,15}$. To understand the neutrophil-macrophage interaction resulting in prominent uterine neutrophil accumulation in HFD-fed atER $\alpha$ KO mice in our study, the regulation of neutrophil signals in uteri was first studied. So called "Don't eat me" signals" on viable neutrophils such as CD47 and PAI-1 ${ }^{14}$ did not differ in uteri from CD- and HFD-fed atER $\alpha$ KO mice (Fig. 2F). However, mRNA expression analysis of M1- and M2 macrophage markers in uteri from atER $\alpha \mathrm{KO}$ mice revealed a statistical non-significant increase of the M1-marker Nos2, but more importantly a highly significant reduction of the M2-marker Arg1 by HFD (Fig. 2G). These data suggest that HFD does not directly affect signals on neutrophils but more likely augments neutrophil presence at the site of infection by an indirect shift in macrophage polarization towards pro-inflammatory conditions and resulting in a significant repression of M2 macrophages. A similar trend could be registered in the expression of Arg1 in white adipose 
tissue, however, no alteration of Nos2 expression could be detected (Fig. 2H). These data suggest that the macrophage phenotype may be regulated in a tissue-specific manner in our model, and that the bacterial environment is, at least in part, required for the enhanced presence of M1 macrophages in the uteri.

To sum up, we show that HFD-feeding promotes a severe bacterial uterine infection in atER $\alpha \mathrm{KO}$ mice likely causing higher mortality. Uterine bacterial infection in HFD-fed atER $\alpha \mathrm{KO}$ mice is characterized by an excess of uterine neutrophil and M1/M2-macrophage imbalance.

HFD-feeding impairs amplified ER $\alpha$ signaling in atER $\alpha$ KO mice. In order to understand the underlying mechanism leading to fatal bacterial infections in atER $\alpha$ KO mice through "simple" HFD-feeding, additional plasma and expression analysis in wt- and atER $\alpha \mathrm{KO}$ mice were performed. Antonson and colleagues recently found that aP2-Cre-mediated deletion of ER $\alpha$ not only results in ER $\alpha$ depletion in adipose tissue but also in the hypothalamus ${ }^{13}$. In agreement with these findings, ER $\alpha$ mRNA expression was significantly reduced in white adipose tissue and hypothalamus but not in the uterus (Fig. 3A). According to the study of Antonson and colleagues, we found that atER $\alpha \mathrm{KO}$ female mice are infertile and have no proper estrous cycle compared to wt, as demonstrated by evaluation of vaginal smear (Fig. S1). E2 levels were also significantly higher in atER $\alpha$ KO- compared to wt-mice (CD: $40.2 \pm 4.6$ vs. $6.1 \pm 2.0 \mathrm{pg} / \mathrm{ml}$; HFD: $45.9 \pm 5.7$ vs. $19.7 \pm 3.4 \mathrm{pg} / \mathrm{ml} ; \mathrm{P}<0.001)$ suggesting enhanced estrogen signaling in atER $\alpha$ KO mice on CD and HFD (Fig. 3B). Accordingly, E2/ER $\alpha$-target genes were markedly upregulated in $\mathrm{CD}$-fed atER $\alpha \mathrm{KO}$ mice, in organs still expressing ER $\alpha$ such as uterus and spleen (Fig. 3C, white bars). Of note was that under HFD ER $\alpha$-target gene induction in uterus and spleen did no longer reach statistical significance (Fig. 3C, black bars) despite high E2-levels implicating impairment of ER $\alpha$ - signaling by HFD. To identify potential mediators in HFD responsible for disturbed ER $\alpha$-signaling plasma lipid analysis using HPLC/ triplequad mass spectrometry was performed. As shown in Fig. 3D, HFD feeding resulted in the regulation of distinct plasma fatty acids (FA) among which C18:0 (stearic acid), C18:2n6 (linoleic acid), and C20:4n6 (arachidonic acid) were significantly upregulated, and only C18:1n9 (oleic acid) was downregulated. Taken together, atER $\alpha \mathrm{KO}$ mice demonstrated reduced hypothalamic ER $\alpha$ expression levels associated with increased circulating E2-levels leading to enhanced ER $\alpha$ signaling in ER $\alpha$ expressing tissue. HFD-feeding induced a distinct plasma FA-profile accompanied by a blockade of ER $\alpha$ signaling.

C18:0 (stearic acid) impairs E2-mediated macrophage polarization and phagocytotic activity. C18:0 (stearic acid) induces pro-inflammatory processes in macrophages ${ }^{16}$ whereas E2 exerts anti-inflammatory actions in these cells ${ }^{17}$. Plasma level of C18:0 showed the strongest up-regulation by HFD feeding in our model. To answer whether the HFD-induced rise in plasma FAs accounts for M1/M2-macrophage imbalance, disturbed neutrophil depletion and exaggerated bacterial inflammation in atER $\alpha$ KO mice, the effect of C18:0 on macrophage M1/M2 polarization in the presence of high E2 was characterized. As previously mentioned, depletion of CD206-positive macrophages (alternatively activated/M2 polarized) can lead to aggravation of inflammatory processes characterized by accumulation of neutrophils at the inflammatory sites. Stimulation of THP-1 macrophages with C18:0 on an E2-background significantly induced CCR7 mRNA levels, a marker for M1 macrophages, and significantly suppressed the expression of CD206, independently from the presence of lipopolysaccharide (LPS) (Fig. 4A). Immunostaining (Fig. 4B) and flow cytometry (FACS) - analysis (Fig. 4C,E) of CD209 (M2-marker ${ }^{18,19}$ ) in THP-1 cells, confirmed the repression of M2-polarization by C18:0. FACS analyses show that the MFI (mean fluorescence intensity) of viable (7AAD negative) CD209 positive cells (left upper quarter of the third column of plots) is significantly decreased from 92.35 to 73.02 (E2 and LPS co-treatment) and from 99.26 to 78.02 (only E2 co-treatment) due to C18:0 action. CD11b, an activation marker and an important integrin for immune cell adhesion, was not significantly regulated (Fig. 4C,D), but shows a slight tendency towards a decrease of CD11b induced by C18:0. Stimulation with the FA leads to a decrease of the average MFI from 1076.33 to 719.36 (E2 and LPS co-treatment) and from 976.56 to 724.82 (only E2 co-treatment). These data show that C18:0 is capable of blocking E2-mediated M2-macrophage polarization, a process important for E2's anti-inflammatory capacity. Furthermore the functionality of macrophages in the presence of C18:0 was tested. The addition of the fatty acid negatively influenced phagocytotic activity of THP-1 macrophages (Fig. 4F). Similar effects on the functionality of macrophages were observed in mice lacking ER $\alpha$ in myeloid cells 9 .

C18:0 induces acylation of ER $\alpha$-immunoprecipitates and inhibits ERE-activity. How does C18:0 impair ER $\alpha$ signaling and E2-mediated macrophage polarization? The Th2 cytokine interleukin 4 (IL4) and the corresponding IL4-receptor promote M2-macrophage polarization ${ }^{20}$. E2-dependent IL4-receptor mRNA expression in primary murine bone marrow-derived macrophages was significantly reduced by co-stimulation with C18:0 (Fig. 5A). In accordance, C18:0 potently blocked E2-dependent ERE-activity in ER $\alpha$-overexpressing THP-1 macrophages (Fig. 5B). Acylation of ER $\alpha$ has been recently shown to directly regulate ER $\alpha$-dependent transcriptional activity via the ER $\alpha$ cysteine $(\mathrm{C})$ residue $447^{21}$. Mutation of ER $\alpha \mathrm{C} 447$ (C447A) resulted in a noticeable attenuation of C18:0's inhibitory action on E2-dependent ERE-activity in comparison to ER $\alpha$ wt (Fig. 5C) suggesting that this residue is, at least partly, involved in C18:0's repressive actions on ER $\alpha$. To see whether C18:0 impairs ER $\alpha$-activity via binding to the receptor complex, we performed $E R \alpha$-immunoprecipitation (IP) experiments after E2 \pm C18:0 stimulation followed by HPLC/triplequad mass spectrometry for FA-detection (Fig. 5D,E). Co-treatment with C18:0 did result in an increased content of a FA in the protein precipitate suggesting an enhanced interaction between FAs and the receptor complex. Interestingly, binding of the monounsaturated FA C18:1n9 to $\mathrm{ER} \alpha$ was significantly induced by $\mathrm{C} 18: 0$ stimulation whereas C18:0 itself was not detectable in IPs suggesting FA-desaturation after stimulation. These results indicate, C18:0 potently inhibits E2-dependent $\mathrm{ER} \alpha$-transcriptional activity potentially involving acylation of the receptor or the receptor multi-protein complex. 
A

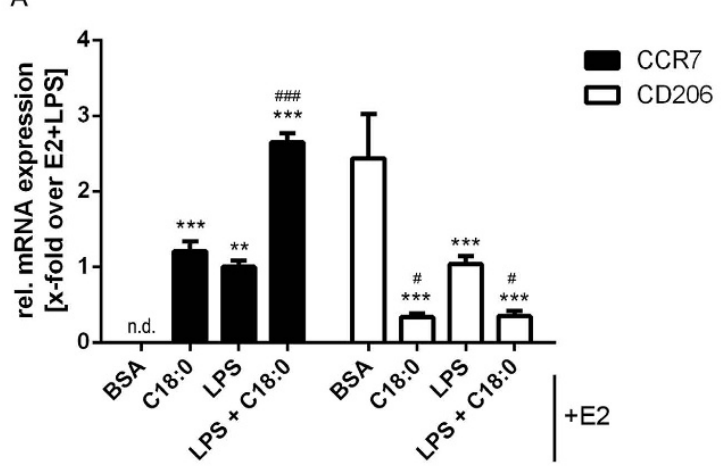

C
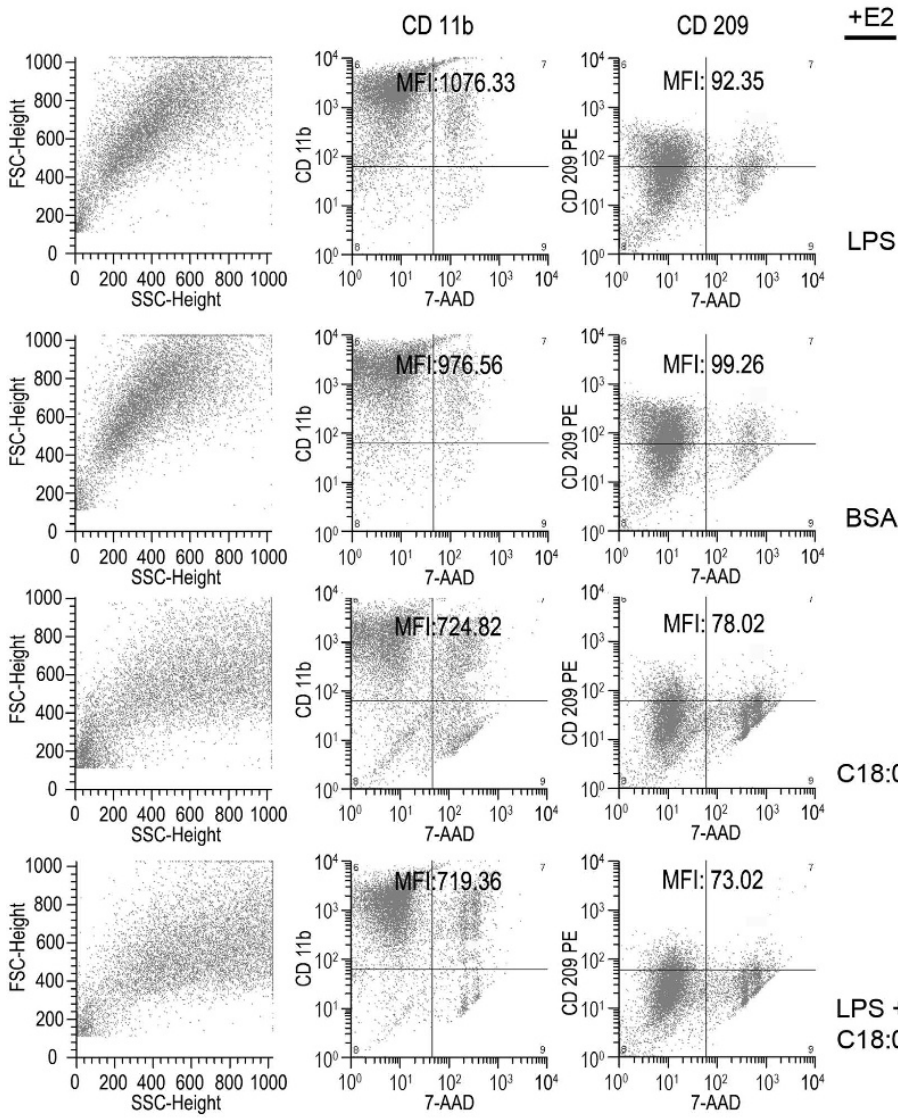

LPS +
B

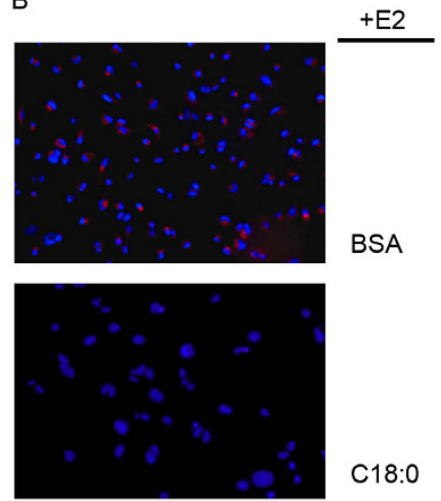

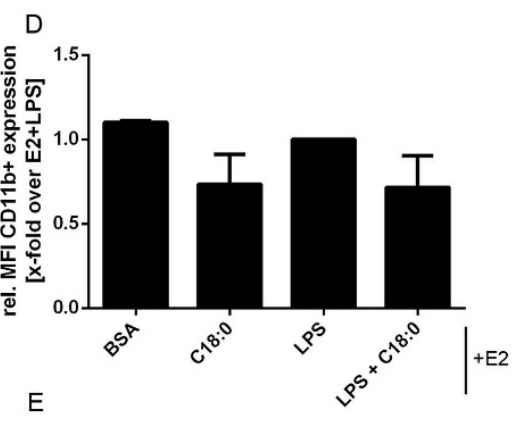

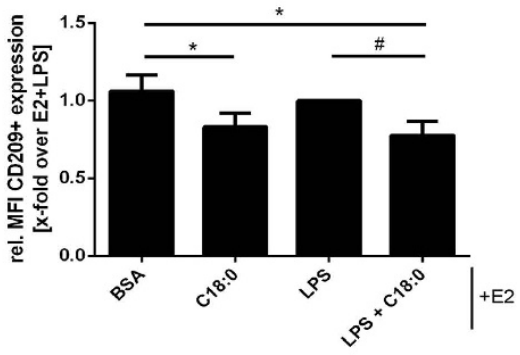

$\mathrm{F}$
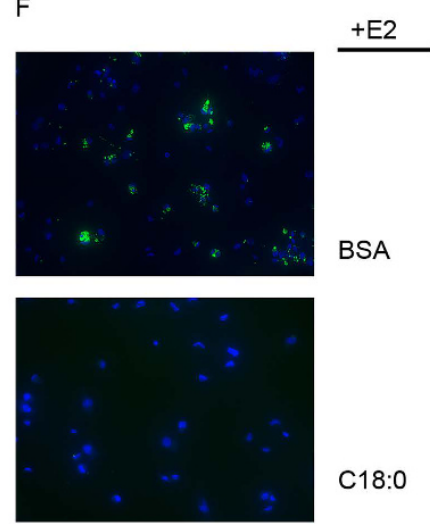

C18:0

Figure 4. Impact of stearic acid on macrophage polarization (and function). Characterization of M1- and M2-markers on differentiated THP-1 cells after stimulation with estradiol (E2)+BSA, E2+C18:0, E2+LPS and E2+LPS+C18:0. (A) Relative mRNA-expression of CCR7 (M1) and CD206 (M2) over E2+LPS stimulated cells. (B) Representative images of CD209 (M2-marker) staining of E2+BSA or E2+C18:0 stimulated THP-1 cells. (C) Representative FACS-dot plots of CD11b and CD209-staining. First column represents unstained cells in forward (FSC) and side scattered blots (SSC); second column shows staining of CD11b- (y-axis) and 7AAD- (x-axis) staining. The third column is analogous to the second one for CD209-staining. Average MFI of viable (7AAD negative) CD11b positive cells (left upper quarter of the blots) and MFI of viable CD209 cells are indicated. (D) Relative mean-fluorescence-intensity of cd11-positive cells and (E) relative mean-fluorescenceintensity of cd209-positive cells (x-fold induction over E2/LPS-stimulated cells). (F) Representative images of phagocytotic analysis of E2+BSA or E2+C18:0 stimulated THP-1 cells. ${ }^{* *} \mathrm{P}<0.01,{ }^{* * *} \mathrm{P}<0.001$ vs. E2+BSA; ${ }^{\#} \mathrm{P}<0.05,{ }^{\# \#} \mathrm{P}<0.001$ vs. $\mathrm{E} 2+\mathrm{LPS}(\mathrm{n}=3$; one-way-ANOVA). 
A

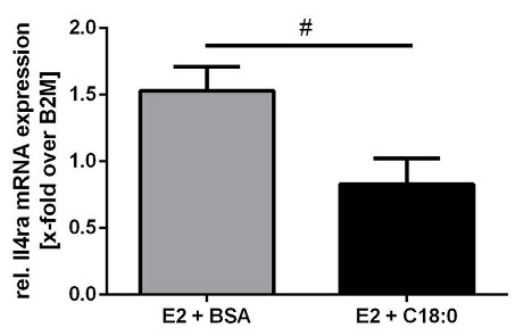

B

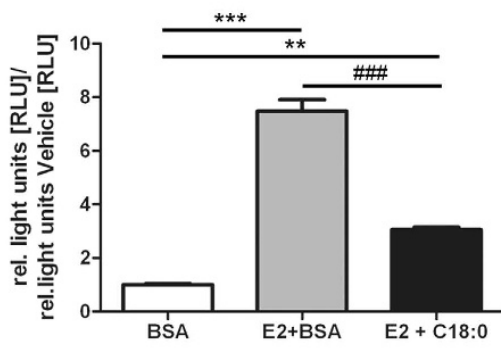

C

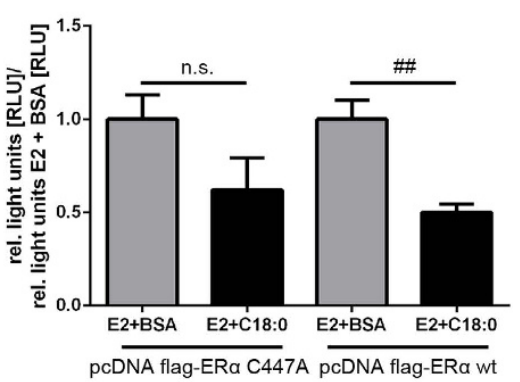

D

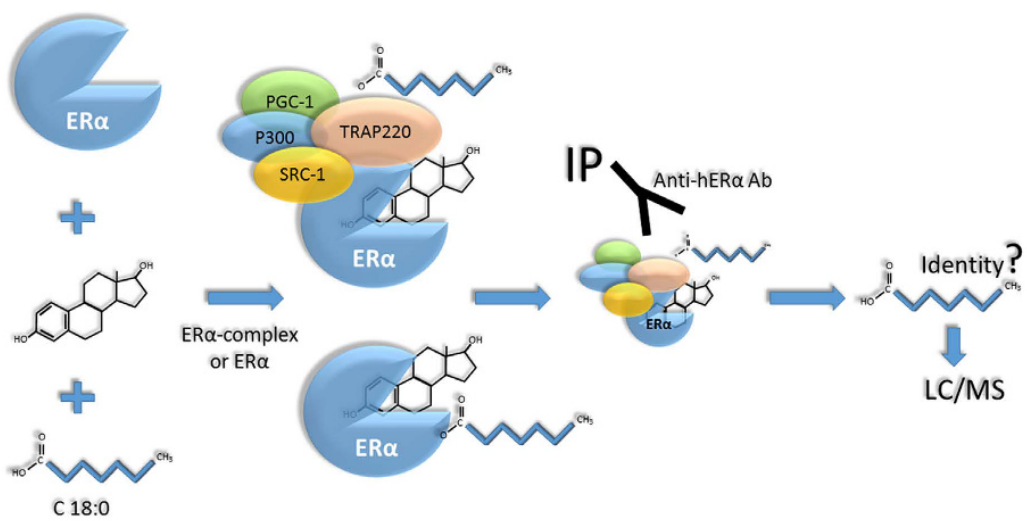

$\mathrm{E}$

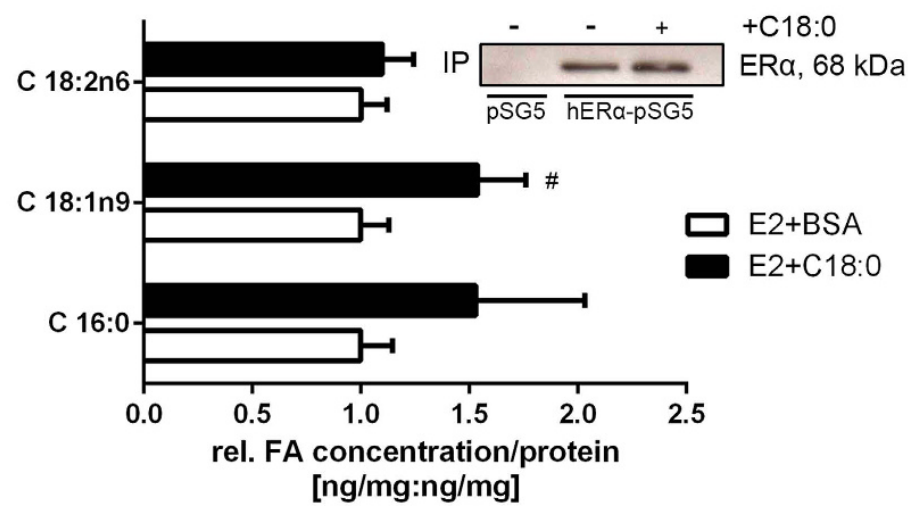

Figure 5. Stearic acid modulation of ER $\alpha$ transcriptional activity. (A) Relative mRNA expression of IL4receptor after stimulation with E2 and C18:0 in primary murine bone marrow-derived macrophages $(n=7-9$ per condition). (B) Inhibition of ligand-dependent activation of ERE by C18:0 in THP- 1 cells $(\mathrm{n}=3-8$ per condition). (C) Inhibition of E2-induced ERE-activity by C18:0 in cells transiently expressing mutated C447A (left bars) or wt (right bars) ER $\alpha$. (D) Experimental settings of HPLC/MS lipid analysis from protein (ER $\alpha$ ) precipitates (E) Relative concentration of main fatty acids bound to ER $\alpha$ per $1 \mathrm{mg}$ protein. (inlay: IP- and transfection-controls by Western-Blot (cropped) of transfected HeLa cells with pSG5 and hER $\alpha$-pSG5 plasmids; full-length blot was provided as supplemental data). ${ }^{\#} \mathrm{P}<0.05,{ }^{\# \#} \mathrm{P}<0.01,{ }^{\# \# \#} \mathrm{P}<0.001$ vs. $\mathrm{E} 2+\mathrm{BSA} ;{ }^{* *} \mathrm{P}<0.01$, ${ }^{* * *} \mathrm{P}<0.001$ vs. vehicle; (one-way-ANOVA or unpaired t-test).

\section{Discussion}

$\mathrm{ER} \alpha$ exerts multiple metabolic actions in adipose tissue $\mathrm{e}^{7}$. To prove that adipose ER $\alpha$ plays a crucial role for whole body metabolism, we investigated the role of ER $\alpha$ in a tissue specific knock-out model using aP2-Cre ${ }^{-1+} / \mathrm{ER}^{\mathrm{fl} / \mathrm{fl}}$ mice. A similar approach has previously been conducted by Davis and colleagues. This demonstrated that, in adiponectin promoter driven-Cre transgenic mice crossed with floxed ER $\alpha$ mice, a lack of ER $\alpha$ in adipose tissue results in an increase of gonadal adipose tissue mass, enhanced adipose tissue fibrosis and inflammation, and in 
glucose intolerance in male mice ${ }^{8}$. Due to an unexpected mortality increase in HFD-fed atER $\alpha$ KO mice, based on a severe bacterial infection, interpretation of the metabolic data in our study are limited which prompted us to focus on the etiology of the uterine infection in our model. The observed discrepancies between Davis and our data likely result from differences in the utilized Cre lines.

In line with Mullican and colleagues and other investigators, we observed that the aP2-Cre model lacks specificity for adipose tissue, reducing ER $\alpha$ mRNA levels also in the hypothalamus ${ }^{22}$. Hypothalamic ER $\alpha$ appears to be important for regular uterine development. Antonson and colleagues recently showed that female aP2-Cre ${ }^{-/+} /$ $\mathrm{ER} \alpha^{\mathrm{fl} / \mathrm{fl}}$ fed a CD display a reproductive phenotype involving infertility, hyperplasia and hydrometra of the uterus $^{13}$. Moreover, other knock-out models of ER $\alpha$ in the brain such as the CamKIIa-Cre-mediated model, also display an enlarged and fluid-filled uterus ${ }^{23}$. Uterine pathologies observed in these models, including this, presumably involve a lack of a central ER $\alpha$-dependent negative feedback resulting in elevated E2-levels subsequently affecting uterine development. Furthermore, elevated E2-levels likely conceal some of the metabolic effects usually expected in mice lacking ER $\alpha$ exclusively in adipose tissue.

The present study, however, is the first report of increased mortality in aP2-Cre $\mathrm{C}^{-/+} / \mathrm{ER}^{\mathrm{f} / \mathrm{fl}}$ mice. In contrast to previous studies, a severe bacterial, E. coli/Enterococcus sp. positive, uterine infection was observed. Since HFD-feeding is the obvious difference between Antonson's ${ }^{13}$ and this study, analysis was conducted to see whether HFD content, in particular FAs, act as pathogenic mediators of disturbed bacterial defense. HFD is well known to induce pro-inflammatory processes on the tissue- and systems level ${ }^{24,25}$. Indeed, in contrast to atER $\alpha \mathrm{KO}$ mice on $\mathrm{CD}$, a severe inflammatory response was identified in uterine tissue from mice fed a HFD characterized by massive neutrophil accumulation and a reduced number of uterine M2-macrophages. Defects of neutrophil clearance have been linked to severe inflammation including sepsis ${ }^{26}$. Neutrophil clearance from the infectious site is a complex process predominantly orchestrated by neutrophils themselves and macrophages ${ }^{14,26,27}$. Anti-inflammatory (M2 polarized) macrophages seem to especially be required for neutrophil clearance and play a crucial role in the resolution of inflammation ${ }^{15,28}$. It was hypothesized that the HFD-induced atER $\alpha \mathrm{KO}$ mice phenotype is mainly a result of HFD-mediated blockade of anti-inflammatory E2-ER $\alpha$-actions. E2-dependent ER $\alpha$ activation usually induces M2-macrophage polarization, and thus attenuating inflammatory responses ${ }^{9,17}$. Under a normal diet, elevated E2 levels in atER $\alpha \mathrm{KO}$ mice lead to enhanced E2-signaling and likely to containment of the inflammatory response. In contrast under HFD, it was shown that C18:0, most strongly up-regulated in plasma from HFD-fed mice, inhibits E2-induced ER $\alpha$-activation significantly blocking E2-stimulated M2-macrophage polarization, and probably exaggerating inflammation. In consonance, C18:0 has been already described to possess pro-inflammatory effects on macrophages ${ }^{16}$. In summary these data suggest that the inflammatory control by E2 is abolished by C18:0 triggering the multifactorial process that induces fatal bacterial infections in this model. Depending on the used ap2-Cre strain, it is known that the targeted gene can be also affected in macrophages ${ }^{29,30}$ opening the possibility of reduced ER $\alpha$ expression. However, this seems not to be the case in the aP2-Cre strain used in our study. Using the identical strain, Mayoral et al. recently showed that macrophages in this strain do not express Cre-recombinase ${ }^{31}$. In line with this findings, in CD-fed aP2-Cre ${ }^{-1+} / \mathrm{ER}^{\mathrm{fl} / \mathrm{fl}}$ mice we still observed a robust induction of the ER $\alpha$ target gene CTSD by E2 in the spleen, a gene highly expressed in macrophages. These data suggest an existing $\mathrm{E} 2$ response in macrophages in $\mathrm{CD}$-fed $\mathrm{aP} 2-\mathrm{Cre}^{-/+} / \mathrm{ER \alpha}^{\mathrm{fl} / \mathrm{fl}}$ mice rendering it unlikely that macrophages lack ER $\alpha$.

Finally, the molecular mechanism of C18:0's repressive action on E2-ER $\alpha$-signaling was investigated. Stearoylation of proteins has been recently identified as a new determinant of protein function ${ }^{32}$. Senyilmaz and colleagues demonstrated that C18:0 stearoylates the human transferrin receptor 1 (TFR1), a protein important for mitochondrial function ${ }^{32}$. Other reports had previously shown the existence of an interaction between ER $\alpha$ and long-chain fatty acids ${ }^{33}$. Stearic acid was described to inhibit E2-effects by downregulation of ER $\alpha$ in hypothalamic tissue ${ }^{33}$, while palmitic acid (C16:0) promotes extra-nuclear action of ER $\alpha$ and prevents its degradation through acylation ${ }^{21}$. In the work of La Rosa and colleagues, the lack of ER $\alpha$-palmitoylation at cysteine (C) residue 447 was shown to repress its transcriptional activity in HEK293 cells ${ }^{21}$. Contrastingly, we observed a significant decrease in E2-induced ERE-activity with C18:0 in differentiated THP-1 macrophages, also likely mediated via C447. HPLC/triplequad MS-based profiling of FAs bound to immunoprecipitated ER $\alpha$ demonstrated a significant protein-FA interaction between $\mathrm{ER} \alpha$, its protein co-factors and $\mathrm{C} 18: \ln 9$ (oleic acid), the main metabolite of C18:0 after enzymatic transformation through the stearoyl-CoA desaturase-1 (SCD-1) ${ }^{34}$. Predominance of cellular C18:1n9 after C18:0 stimulation is not surprising, since it has long been known that desaturation of C18:0 is greater than compared to other saturated $\mathrm{FAs}^{35}$. Up until now, the following mechanism can be proposed: challenge of macrophages with $\mathrm{C} 18: 0$ leads to repression of ER $\alpha$-transcriptional activity potentially involving the direct interaction between FAs and the of ER $\alpha$ transcriptional protein complex. The relative contribution of the direct FA - ER $\alpha$-complex interaction to the observed phenotype in HFD-fed atER $\alpha$ KO mice requires further experiments.

The importance of these data is further supported by clinical observations in female dogs. In sexually mature female dogs, pyometra is a common disease entity ${ }^{36}$. Up until now, the pathogenesis has been linked to increased estradiol levels and prolonged progesterone stimulation ${ }^{36}$. In light of our findings, it might be worth to investigate the relevance of dietary FAs in conjunction with high E2/progesterone levels for the pathogenesis of canine pyometra. Along this line, these findings might also be relevant for bacterial uterine infections in humans when conditions occur in which frequent HFD consumption is combined with high plasma E2-levels, e.g. during pharmacological application.

This study identifies an unexpected phenotype of atER $\alpha$ KO mice fed HFD characterized by increased mortality likely due to fatal bacterial uterine infections driven by commensal microbes. This phenotype points towards a previously unknown interaction of ER $\alpha$ signaling and FAs in macrophages. In particular, it was shown that C18:0 provided by HFD impairs E2-ER $\alpha$ action in macrophages with a concomitant perturbation of M2-macrophage polarization usually required for regular neutrophil-mediated bacterial defense. In accompanying in-vitro 
experiments we identified a direct interaction between FAs and the intracellular ER $\alpha$ transcriptional complex associated with a C18:0-mediated inhibition of ER $\alpha$ transcriptional activity and E2-dependent regulation of genes involved in M2 macrophage polarization. These data suggests a new mechanism of how FAs are capable of disturbing macrophage E2-ER $\alpha$-signaling thereby aggravating commensal bacterial infections at predilection sites.

Therefore, it is suggested a new mechanism of dietary FA interference with ER $\alpha$ resulting in the impairment of E2-mediated anti-inflammatory actions and the promotion of severe bacterial uterine infections.

\section{Materials and Methods}

Mice. Female adipose tissue-specific (aP2) - mice were generated by crossing B6.Cg-Tg(Fabp4-cre)1Rev/J mice with B6.129X1-Esr1tm1Gust $\left(\mathrm{ER \alpha}^{\mathrm{fl} / \mathrm{fl}}\right)$ mice, kindly provided by J.-A. Gustafsson (University of Houston, TX, USA). ER $\alpha^{\mathrm{f} / \mathrm{fl}} / \mathrm{aP} 2-\mathrm{Cre}^{-/+}($atER $\alpha \mathrm{KO})$ and control littermates $\mathrm{ER}^{\mathrm{fl} / \mathrm{fl}} / \mathrm{aP} 2-\mathrm{Cre}^{-/-}$(wt) were used for all experiments. Animals were maintained in a temperature-controlled facility with a $12 \mathrm{~h}$ dark/light cycle. At the age of 6 weeks, a group of atER $\alpha \mathrm{KO}$ and wt-mice $(\mathrm{n}=24)$, were challenged for 14 weeks with a HFD $(60 \% \mathrm{kcal}$ from fat, Brogaarden, Lynge, Denmark). The HFD groups and the CD were both fed ad-libitum. Metabolic phenotyping was performed with a metabolic cage system (TSE- Systems GmbH, Bad Homburg, Germany), based on indirect calorimetry as described before ${ }^{12}$. Body composition was assessed by nuclear magnetic resonance imaging (Echo MRI mouse, Echo Medical Systems, Houston, USA). Body temperature was measured rectally 3 to 5 days in row and mean values were calculated. Wt-mice were sacrificed during estrous phase of the cycle. atER $\alpha$ KO mice did not present a physiological estrous cycle, and were sacrificed independent of (non-) cycle phases; their vaginal smear was collected and analyzed to exclude a proestrous analogous stage. Organs were collected and frozen in liquid nitrogen. All animal experiments were approved by the Landesamt für Gesundheit und Soziales (LaGeSo, Berlin, Germany) and were conducted in alliance with the German Law on the Protection of Animals.

Cell culture. THP-1 cells (American Type Culture Collection (ATCC)) were cultured in RPMI 1640 (Life Technologies) with 1\% Pen-Strep (Invitrogen) and 10\% charcoal-stripped fetal bovine serum (cs-FBS; Sigma Aldrich). THP-1 cells were differentiated for 48 hours with $10 \mathrm{ng} / \mathrm{ml}$ phorbol myristate acetate (Sigma Aldrich). Prior to stimulation, cells were kept in phenol red-free medium for $48 \mathrm{~h}$ and starved overnight (12 h) with phenol red-free RPMI medium reducing the content of cs-FBS to $2.5 \%$. Next, cells were stimulated for $24 \mathrm{~h}$ with $10 \mathrm{nM}$ E2 (Sigma), $50 \mu \mathrm{M}$ solution of stearic acid (C18:0) in 10\% BSA (Sigma Aldrich), or with 10\% BSA alone (control). Lipopolysaccharide ( $100 \mathrm{nM}$, LPS) from E. coli (Sigma) was added $2 \mathrm{~h}$ prior to harvesting with lysis buffer (Qiagen). For luciferase reporter assay passive lysis buffer (Promega) was used.

Bone-marrow derived macrophages (BMDM) were isolated as described before ${ }^{37}$, using $10 \%$ L929-conditioned medium for macrophage differentiation. RPMI with 10\% cs-FBS and 1\% Pen-Strep was used to differentiate and cultivate cells. For stimulation, phenol red-free medium was used with addition of E2, BSA and C18:0 in the same concentrations as done with THP-1 cells.

HeLa cells (ATCC) were cultured in Dulbecco's Modified Eagle Medium (DMEM) with addition of 10\% cs-FBS and 1\% Pen-Strep. Prior to stimulation with E2+BSA, or E2+C18:0 (analogously to THP-1 cells), cells were transfected as described below.

Gene expression analysis. RNA from cultured THP-1 cells, and BMDM, from adipose tissue, uteri and hypothalamus was isolated with RNeasy Mini Kit (Qiagen) following the manufacturer's instructions. For real-time PCR analysis, RNA was reverse transcribed and relative mRNA expression was normalized to $18 \mathrm{~S}$ (animal tissues), $\beta 2$-microglobulin (BMDM) or to $\beta$-Actin (THP-1 cells). Primer sequences will be provided on demand.

17 $\beta$-estradiol measurement in plasma. Plasma samples of atER $\alpha \mathrm{KO}$ and wt mice were obtained after final blood collection. The measurement of $17 \beta$-estradiol (E2) concentrations was performed by a radioimmunoassay set up as a sequential assay as previously described ${ }^{38}$. Prior to radioimmunoassay, blood plasma was extracted twice with toluene and the pooled extracts were evaporated to dryness and re-dissolved. The antiserum used was directed against E2-6-carboximethyloxim (CMO)-BSA and exhibited the following cross-reactions: estrone, $1.3 \%$; estriol, $0.7 \%$; all tested non-phenolic steroids $<0.01 \%$. The minimum detectable concentration was $5 \mathrm{pg} / \mathrm{ml}$; intra- and interassay coefficient of variation $(\mathrm{CV})$ were 7.1 and $17.6 \%$, respectively.

Fatty acid profiling in plasma samples and in protein precipitates. Fatty acids were analysed in plasma samples from atER $\alpha$ KO mice on CD and HFD with a triplequad mass spectrometer coupled HLPC method, as described before ${ }^{39}$. Briefly, after hydrolysis, samples were diluted 1:10 in methanol containing internal standards. Samples were injected and separated by a reverse-phased column (Phenomenex Kinetex-C18 column $2.6 \mu \mathrm{m}, 2.1 \times 150 \mathrm{~mm}$ ) with a solvent gradient containing aqueous formic acid $(0.1 \%)$ and acetonitrile. After separation of components, fatty acid's identity was analysed by an Agilent 6460 triplequad mass spectrometer with electrospray ionisation.

Histology. After sacrificing mice, uteri were partly fixed with $4 \%$ formalin, and paraffin-embedded. Sections were deparaffinised with xylene and rehydrated with a gradient of alcoholic solutions. Antigen heat retrieval with citric acid and incubation with goat serum was performed with slides prior to hematoxylin and eosin (H\&E), monoclonal rat anti-mouse Mac3 antibody (clone M3/84, BD Pharmingen, USA), and monoclonal rat anti-mouse Ly6G antibody (clone 1A8, Biolegend, USA) staining. For evaluation of the grade of inflammation, and for Mac3 and Ly6G expression a semi-quantitative scoring system was applied, using a standardized procedure under observation of the equivalent anatomical structures of the uteri. 
Flow cytometry. For FACS analysis, THP-1 macrophages were stained with PE conjugated anti-CD11b (BioLegend Inc. San Diego, USA) or PE conjugated anti-CD209 (BioLegend), and 7-AAD (Cell Viability Solution, BioLegend). FACS analysis was performed on a FACS Calibur flow cytometer (BD Biosciences, Heidelberg, Germany). As cells were only single stained, auto fluorescence controls were used to set negatives. The expression of the constitutively expressed adhesion protein CD11b and the M2-marker CD209 was quantified as mean fluorescence intensity (MFI). Relative up- or downregulation of CD11b- and CD209-expression was calculated by the following equation: MFI (CD11b (or CD209) of cells)/MFI (CD11b (or CD209) of E2+LPS treated cells). 7-AAD-staining was used to determine and exclude dead cells.

Phagocytosis assay and immunofluorescence staining. For testing of phagocytosis activity, phagocytosis Assay Kit (Cayman) was used and performed in accordance to the manufacturer's instructions. Briefly, FITC-labelled beads were added to the supernatant and THP-1 macrophages were processed analogously as for immunostaining experiments. For immunostaining cells were fixed with formalin and blocked with goat serum. Afterwards, cells were incubated with PE conjugated anti-CD209 antibody (Biolegend), washed, stained with DAPI (1:1000, Thermo Scientific, blue) and mounted with mounting medium (Dako). Three fluorescent pictures were captured randomly from every sample ( $n=6$ per group) with an all-in-one fluorescence microscope (BZ-9000E, Keyence). Finally, representative pictures were selected.

Luciferase reporter assay. After plating and differentiating THP-1 cells as described above, cells were transiently transfected with hER $\alpha$-pSG5 (kindly provided by P. Chambon, Institut Clinique de la Souris, Illkirch Cedex, France), or with pcDNA flag ER $\alpha$ wt or pcDNA flag ER $\alpha$ C447A (kindly provided by F. Acconcia, University Roma Tre, Rome, Italy), and with pERE-TkGL3 (kindly provided by P.J. Kushner, Metabolic Research Unit and Diabetes Center, University of California, San Francisco, USA), and pRL-CMV (Promega), a renilla luciferase vector. Transfection was performed with jetPEI ${ }^{\circledR}$ - Macrophage transfection reagent (Polyplus-transfection) according to the manufacturer's instructions. Prior to stimulation, cells were starved for a maximum of $10 \mathrm{~h}$. After harvesting, cell lysates were used to measure luciferase activity with the dual-luciferase reporter assay system (Promega).

Immunoprecipitation. For ER $\alpha$-immunoprecipitation, HeLa cells (ATTC) were transfected with $3 \mu \mathrm{g}$ hER $\alpha$-pSG5 or pSG5 using Lipofectamine ${ }^{\circledR} 2000$ (Thermo Scientific) and OptiMEM (Invitrogen). $24 \mathrm{~h}$ after transfection, cells were stimulated for $24 \mathrm{~h}$ with E2 and/or C18:0, in concentrations as described for THP-1 cells. Cells were lysed with RIPA (with proteinase-inhibitors, Complete Mini, Roche), sonicated (Sonopuls HD 2070, 30 s, 40-50\%), and centrifuged. Supernatant was used to perform immunoprecipitation (IP) with anti-ER $\alpha$-antibody (D8H8, Cell Signaling) bound to Protein A Sepharose-beads (Amersham). For western immunoblotting a distinct anti-ER $\alpha$-antibody (sc-8002, Santa Cruz) was used. Washed beads-antibody-ER $\alpha$ complexes were analysed for fatty acids- binding as described above.

Statistical analysis. All experiments were repeated at least three times and n-numbers are indicated for each experiment. Statistical analysis was performed with GraphPad Prism Software and statistical significance was assumed at $\mathrm{p}<0.05$. Comparison of mean values was evaluated by two-way ANOVA (Bonferroni posttest), two-way ANOVA with repeated measures (Bonferroni posttest), or unpaired t-tests, as appropriate.

\section{References}

1. Palmer, B. F. \& Clegg, D. J. The sexual dimorphism of obesity. Mol Cell Endocrinol 402, 113-119, doi: 10.1016/j.mce.2014.11.029 (2015).

2. Toth, M. J., Tchernof, A., Sites, C. K. \& Poehlman, E. T. Menopause-related changes in body fat distribution. Ann N Y Acad Sci 904, 502-506 (2000).

3. Deroo, B. J. \& Korach, K. S. Estrogen receptors and human disease. J Clin Invest. 116, 561-570. (2006).

4. Stubbins, R. E., Holcomb, V. B., Hong, J. \& Nunez, N. P. Estrogen modulates abdominal adiposity and protects female mice from obesity and impaired glucose tolerance. Eur J Nutr, doi: 10.1007/s00394-011-0266-4 [doi] (2011).

5. Heine, P. A., Taylor, J. A., Iwamoto, G. A., Lubahn, D. B. \& Cooke, P. S. Increased adipose tissue in male and female estrogen receptor-alpha knockout mice. Proc Natl Acad Sci USA 97, 12729-12734 (2000).

6. Foryst-Ludwig, A. et al. Metabolic actions of estrogen receptor beta (ERbeta) are mediated by a negative cross-talk with PPARgamma. PLoS Genet 4, e1000108, doi: 10.1371/journal.pgen.1000108 (2008).

7. Hevener, A. L., Clegg, D. J. \& Mauvais-Jarvis, F. Impaired estrogen receptor action in the pathogenesis of the metabolic syndrome. Mol Cell Endocrinol, doi: 10.1016/j.mce.2015.05.020 (2015)

8. Davis, K. E. et al. The sexually dimorphic role of adipose and adipocyte estrogen receptors in modulating adipose tissue expansion, inflammation, and fibrosis. Molecular metabolism 2, 227-242, doi: 10.1016/j.molmet.2013.05.006 (2013).

9. Ribas, V. et al. Myeloid-specific estrogen receptor alpha deficiency impairs metabolic homeostasis and accelerates atherosclerotic lesion development. Proc Natl Acad Sci USA 108, 16457-16462, doi: 10.1073/pnas.1104533108 (2011).

10. Xu, Y. et al. Distinct hypothalamic neurons mediate estrogenic effects on energy homeostasis and reproduction. Cell Metab 14, 453-465, doi: 10.1016/j.cmet.2011.08.009 (2011).

11. Homma, H. et al. Estrogen suppresses transcription of lipoprotein lipase gene. Existence of a unique estrogen response element on the lipoprotein lipase promoter. J Biol Chem 275, 11404-11411 (2000).

12. Benz, V. et al. Sexual dimorphic regulation of body weight dynamics and adipose tissue lipolysis. PLoS One 7, e37794, doi: 10.1371/ journal.pone.0037794 (2012).

13. Antonson, P. et al. aP2-Cre-mediated inactivation of estrogen receptor alpha causes hydrometra. PLoS One 9, e85581, doi: 10.1371/ journal.pone.0085581 (2014).

14. Bratton, D. L. \& Henson, P. M. Neutrophil clearance: when the party is over, clean-up begins. Trends in immunology 32, 350-357, doi: 10.1016/j.it.2011.04.009 (2011).

15. Kambara, K. et al. In vivo depletion of CD206+ M2 macrophages exaggerates lung injury in endotoxemic mice. Am J Pathol 185, 162-171, doi: 10.1016/j.ajpath.2014.09.005 (2015). 
16. Anderson, E. K., Hill, A. A. \& Hasty, A. H. Stearic acid accumulation in macrophages induces toll-like receptor 4/2-independent inflammation leading to endoplasmic reticulum stress-mediated apoptosis. Arterioscler Thromb Vasc Biol 32, 1687-1695, doi: 10.1161/atvbaha.112.250142 (2012)

17. Toniolo, A. et al. Alternative activation of human macrophages is rescued by estrogen treatment in vitro and impaired by menopausal status. J Clin Endocrinol Metab 100, E50-58, doi: 10.1210/jc.2014-2751 (2015).

18. Mercalli, A. et al. Rapamycin unbalances the polarization of human macrophages to M1. Immunology 140, 179-190, doi: 10.1111/ imm.12126 (2013).

19. Preza, G. C. et al. Antigen-presenting cell candidates for HIV-1 transmission in human distal colonic mucosa defined by CD207 dendritic cells and CD209 macrophages. AIDS Res Hum Retroviruses 30, 241-249, doi: 10.1089/AID.2013.0145 (2014)

20. Gordon, S. \& Martinez, F. O. Alternative activation of macrophages: mechanism and functions. Immunity 32, 593-604, doi: 10.1016/j.immuni.2010.05.007 (2010).

21. La Rosa, P., Pesiri, V., Leclercq, G., Marino, M. \& Acconcia, F. Palmitoylation regulates 17beta-estradiol-induced estrogen receptoralpha degradation and transcriptional activity. Mol Endocrinol 26, 762-774, doi: 10.1210/me.2011-1208 (2012).

22. Mullican, S. E. et al. A novel adipose-specific gene deletion model demonstrates potential pitfalls of existing methods. Mol Endocrinol 27, 127-134, doi: 10.1210/me.2012-1267 (2013).

23. Wintermantel, T. M. et al. Definition of estrogen receptor pathway critical for estrogen positive feedback to gonadotropin-releasing hormone neurons and fertility. Neuron 52,271-280, doi: 10.1016/j.neuron.2006.07.023 (2006).

24. Hotamisligil, G. S. \& Erbay, E. Nutrient sensing and inflammation in metabolic diseases. Nat Rev Immunol 8, 923-934, doi: 10.1038/ nri2449 (2008).

25. Thaler, J. P. et al. Obesity is associated with hypothalamic injury in rodents and humans. J Clin Invest 122, 153-162, doi: 10.1172/ jci59660 (2012).

26. McCracken, J. M. \& Allen, L. A. Regulation of human neutrophil apoptosis and lifespan in health and disease. J Cell Death 7, 15-23, doi: 10.4137/JCD.S11038 (2014).

27. Schiwon, M. et al. Crosstalk between sentinel and helper macrophages permits neutrophil migration into infected uroepithelium. Cell 156, 456-468, doi: 10.1016/j.cell.2014.01.006 (2014).

28. Campbell, L. et al. Estrogen receptor-alpha promotes alternative macrophage activation during cutaneous repair. J Invest Dermatol 134, 2447-2457, doi: 10.1038/jid.2014.175 (2014).

29. Urs, S., Harrington, A., Liaw, L. \& Small, D. Selective expression of an aP2/Fatty Acid Binding Protein 4-Cre transgene in nonadipogenic tissues during embryonic development. Transgenic research 15, 647-653, doi: 10.1007/s11248-006-9000-z (2006).

30. Mao, J. et al. aP2-Cre-mediated inactivation of acetyl-CoA carboxylase 1 causes growth retardation and reduced lipid accumulation in adipose tissues. Proc Natl Acad Sci USA 106, 17576-17581, doi: 10.1073/pnas.0909055106 (2009).

31. Mayoral, R. et al. Adipocyte SIRT1 knockout promotes PPARgamma activity, adipogenesis and insulin sensitivity in chronic-HFD and obesity. Mol Metab 4, 378-391, doi: 10.1016/j.molmet.2015.02.007 (2015).

32. Senyilmaz, D. et al. Regulation of mitochondrial morphology and function by stearoylation of TFR1. Nature 525, 124-128, doi: 10.1038 /nature14601 (2015).

33. Morselli, E. et al. Hypothalamic PGC-1alpha protects against high-fat diet exposure by regulating ERalpha. Cell reports 9, 633-645, doi: 10.1016/j.celrep.2014.09.025 (2014).

34. Sampath, H. \& Ntambi, J. M. The fate and intermediary metabolism of stearic acid. Lipids 40, 1187-1191 (2005).

35. Bruce, J. S. \& Salter, A. M. Metabolic fate of oleic acid, palmitic acid and stearic acid in cultured hamster hepatocytes. The Biochemical journal 316(Pt 3), 847-852 (1996).

36. Smith, F. O. Canine pyometra. Theriogenology 66, 610-612, doi: 10.1016/j.theriogenology.2006.04.023 (2006).

37. Weischenfeldt, J. \& Porse, B. Bone Marrow-Derived Macrophages (BMM): Isolation and Applications. CSH Protoc 2008, pdb prot5080, doi: 10.1101/pdb.prot5080 (2008).

38. Hoffmann, B., Hoveler, R., Hasan, S. H. \& Failing, K. Ovarian and pituitary function in dogs after hysterectomy. J Reprod Fertil 96, 837-845 (1992).

39. Foryst-Ludwig, A. et al. Adipose Tissue Lipolysis Promotes Exercise-induced Cardiac Hypertrophy Involving the Lipokine C16:1n7Palmitoleate. J Biol Chem 290, 23603-23615, doi: 10.1074/jbc.M115.645341 (2015).

\section{Acknowledgements}

The work was supported by Deutsche Forschungsgemeinschaft (DFG; KFO 218/2 (Ki712/7-1)). ZB and VB were supported by the DFG (KFO 218/1+2). SB was supported by the Deutsche Stiftung für Herzforschung. MR is an employee of Lipidomix GmbH, Berlin, Germany. AFL was supported by the DFG (FG 1054/2, KFO 218/2), the Deutsche Stiftung für Herzforschung, and the DZHK. UK was supported by the DFG (FG 1054/2, KFO 218/2), the Else Kröner-Fresenius Stiftung (2014_A100), and the DZHK. This study was supported by the Robert A. Welch Foundation and by the Swedish Cancer Society.

\section{Author Contributions}

Z.B. substantially contributed to conception and design of the study, acquisition of data, and data analysis and interpretation, drafted the article, and revised the article critically for important intellectual content. P.M. (in-vitro experiments), V.B. and S.B. (in-vivo experiments), A.S. (in-vitro experiments), and G.S. (in-vivo experiments) substantially contributed to acquisition of data, and data analysis and interpretation. M.R. and R.K. substantially contributed to conception of the study, acquisition of data, and data analysis and interpretation (M.R.: HPLC/MS analysis, R.K.: Histological analysis). J.A.G. substantially contributed to conception and design of the study (in-vivo experiments with atER $\alpha \mathrm{KO}$ mice), and data interpretation, and revised the article critically for important intellectual content. A.F.L. substantially contributed to conception and design of the study, acquisition of data, and data analysis and interpretation, and revised the article critically for important intellectual content. U.K. substantially contributed to acquisition of funding, conception and design of the study, data analysis and interpretation, drafted the article, and revised the article critically for important intellectual content. All authors finally approved the version to be published. Parts of this work will be used in the PhD-thesis of Z.B.

\section{Additional Information}

Supplementary information accompanies this paper at http://www.nature.com/srep

Competing financial interests: $\mathrm{MR}$ is an employee of Lipidomix $\mathrm{GmbH}$, Berlin, Germany. All other authors have no conflict of interest to disclose related to the submitted article. 
How to cite this article: Ban, Z. et al. High-Fat Diet Induces Unexpected Fatal Uterine Infections in Mice with aP2-Cre-mediated Deletion of Estrogen Receptor Alpha. Sci. Rep. 7, 43269; doi: 10.1038/srep43269 (2017).

Publisher's note: Springer Nature remains neutral with regard to jurisdictional claims in published maps and institutional affiliations.

(c) (i) This work is licensed under a Creative Commons Attribution 4.0 International License. The images or other third party material in this article are included in the article's Creative Commons license, unless indicated otherwise in the credit line; if the material is not included under the Creative Commons license, users will need to obtain permission from the license holder to reproduce the material. To view a copy of this license, visit http://creativecommons.org/licenses/by/4.0/

(c) The Author(s) 2017 